\title{
Episodic Vestibular Symptoms in Children with a Congenital Cytomegalovirus
} Infection: A Case Series

\section{Running head}

Episodic vestibular symptoms in children with cCMV

\section{Authors}

Cleo Dhondt $(\mathrm{MSc})^{\mathrm{a}}$, Leen Maes $(\mathrm{PhD})^{\mathrm{b}, \mathrm{c}}$, Ann Oostra $(\mathrm{MD})^{\mathrm{d}}$ and Ingeborg Dhooge $(\mathrm{PhD}$, $\mathrm{MD})^{\mathrm{a}, \mathrm{c}}$

${ }^{\text {a} D e p a r t m e n t ~ o f ~ H e a d ~ a n d ~ S k i n, ~ G h e n t ~ U n i v e r s i t y, ~ G h e n t, ~ B e l g i u m ~}$

bepartment of Rehabilitation Sciences, Ghent University, Ghent, Belgium

${ }^{\mathrm{c} D e p a r t m e n t ~ o f ~ O t o r h i n o l a r y n g o l o g y, ~ G h e n t ~ U n i v e r s i t y ~ H o s p i t a l, ~ G h e n t, ~ B e l g i u m ~}$

${ }^{\mathrm{d} C e n t r e}$ for Developmental Disabilities, Ghent University Hospital, Ghent, Belgium

\section{Corresponding Author}

Cleo Dhondt, Department of Head and Skin, Ghent University, Ghent, Belgium

E-mail: Cleo.Dhondt@UGent.be; Phone: 0032933228 89, Fax: 003293324993

Postal address: Ghent University Hospital, Department of Head and Skin, Corneel

Heymanslaan 10 (1P1), B - 9000 Ghent, Belgium

\section{Acknowledgments}

The authors would like to thank Prof. Dr. Els De Leenheer, Prof. Dr. Helen Van Hoecke and Dr. Alexandra De Kegel for introducing some of these interesting cases and their follow-up assessments, as well as the neuropaediatricians following these children for sharing their data, and the parents for giving consent to include the data of their child. 
This research did not receive any specific grant from funding agencies in the public, commercial, or not-for-profit sectors.

26 


\title{
Episodic Vestibular Symptoms in Children with a Congenital Cytomegalovirus
}

\author{
Infection: A Case Series
}

\begin{abstract}
\end{abstract}
Objective: Congenital cytomegalovirus (cCMV) infection is the most common non-genetic cause of sensorineural hearing loss in children. Although cCMV-induced vestibular loss is demonstrated in several studies, the occurrence of vertigo has been described in only two cases to date. The aim of this paper is to discuss the underlying pathophysiology of recurrent vestibular symptoms in children with cCMV, based on five cases investigated in our center and an extensive research of the literature.

Study Design: Retrospective case series.

Setting: Tertiary referral center.

Patients: This case series describes five pediatric cCMV-patients (three boys, two girls). Four of them were symptomatic at birth, one was asymptomatic. Three patients underwent cochlear implantation. The age of onset of the vestibular symptoms varied from $2 ; 0$ to $7 ; 3$ years of age.

\section{Intervention: None}

Main Outcome Measures: Details about the patient history and results of cranial imaging, audiological, vestibular and neurological assessments were collected retrospectively.

Results: The selected cases suffered from recurrent vestibular symptoms. All patients had delayed onset, fluctuating and/or progressive hearing loss. In all cases, the attacks were accompanied with nausea and vomiting and occurred without clear-cut trigger. Migraine and epilepsy often were proposed as first diagnosis, although they could not be confirmed eventually. Four out of five patients were diagnosed with a peripheral vestibular deficit. 
Conclusions: Diagnosis of vestibular symptoms in children with cCMV is complex, given the multiple morbidities than can occur. Peripheral vestibular causes should be considered in the diagnosis, as important vestibular deficits are demonstrated in this population.

\section{KEYWORDS}

Congenital cytomegalovirus infection; vomiting; vestibular; episode; vertigo; recurrent; children.

\section{INTRODUCTION}

Cytomegalovirus infection is the most common viral congenital infection and a major cause of neurodevelopmental delay in children. In industrialized countries, the overall birth prevalence is $0.64 \%$ (1). Only one third of children with a congenital cytomegalovirus (cCMV) infection show clinical symptoms at birth, but all are at risk for long-term sequelae (2). Sensorineural hearing loss (SNHL) is the most common sequel of cCMV-infection, affecting $63 \%$ of the symptomatic and $8 \%$ of the asymptomatic children and leading to cochlear implantation (CI) in about $6 \%$ of the cCMV-patients, as described by Goderis et al. (2). They also reported that cCMV-related SNHL, which is characterized by its unstable nature with possible fluctuations or progression, occurs with delayed onset in 9\% of all cCMV-patients.

cCMV-related vestibular loss was described in 50 to $96 \%$ of the hearing-impaired and 7 to $80 \%$ of the normal-hearing cCMV-patients (3-6). These broad ranges are due to high variability in subject groups and study designs between studies. Progression of cCMV-related vestibular impairment was shown by Bernard et al. (5) in $50 \%$ of the longitudinally followed patients and also described in isolated cases by others $(7,8)$. Besides these sporadic reports, little is known 
about the phenotype and characteristics (onset, evolution, etc.) of the cCMV-related vestibular deficits $(3-7,9)$. Nevertheless, it is plausible that vestibular loss due to cCMV not necessarily results in typical vestibular symptoms such as vertigo, dizziness and nausea. Congenital or bilateral impairment, or steady deterioration of the vestibular function will be reflected in the child's motor development, rather than evoke acute symptoms $(5,10)$.

However, during the past few years, several cCMV-patients did consult our center in the context of recurrent vestibular symptoms. To our knowledge, episodic vertigo in cCMV was reported in only two patients to date. Weiss and Ronis (11) were the first to report vestibular symptoms in a 19-year-old symptomatic cCMV-patient and attributed the symptoms to the development of postinflammatory hydrops. The second patient was a 4-year-old symptomatic patient, described in a case series of Huygen and Admiraal (8) about cCMV-related delayed endolymphatic hydrops.

This study is the first to describe a series of five pediatric cases with cCMV, suffering from episodic vestibular complaints. The aim of this paper is to report on the phenotype of episodic vertigo in relation with cCMV and to gain more insight in the underlying pathophysiology of recurrent vestibular symptoms in pediatric cCMV-patients, based on systematic and detailed report of these five cases and extensive literature research. It is intended to discuss the hydropshypothesis of Weiss and Ronis (11) and Huygen and Admiraal (8) in the light of more recent findings in literature and to propose other plausible causes that should be considered in the differential diagnosis.

\section{MATERIALS AND METHODS}

\subsection{Subjects}

We selected all patients investigated at our center, meeting following three criteria: 
Firstly, patients had to be diagnosed with cCMV. In our center, children 'at risk' for cCMVinfection (e.g. because of a known maternal seroconversion during pregnancy) are routinely tested for cCMV by virus isolation or polymerase chain reaction on a urine sample taken within the first 2 weeks of life. Children diagnosed with cCMV are then subjected to an extensive test battery including physical neurological evaluation, cranial imaging, blood tests and ophthalmologic and hearing assessment. In case of abnormalities on one of these neonatal examinations, the child is defined symptomatic. All others are considered asymptomatic. Antiviral treatment is proposed in symptomatic patients, with the exception of those with bilateral profound SNHL as the only symptom.

Secondly, patients had to suffer from vestibular symptoms. However, the detection of vestibular symptoms in young children can be very challenging, as they may lack appropriate vocabulary or experience to express abnormal sensations. Therefore, this paper focused on patients presenting with clearly detectable clinical symptoms. Although not exclusively characteristic for vestibular disorders, vomiting was the predetermined requirement for inclusion. This was considered the only symptom that could unambiguously be reported by the parents. However, it should be noted that patients only turned to our service in case other vestibular symptoms (such as vertigo, instability) accompanied the vomiting.

Thirdly, the vestibular symptoms had to be recurrent, which we defined as having at least two episodes of malaise.

\subsection{Data collection}

The study was approved by the Ghent University Hospital Ethics Committee. Informed consents were obtained from the parents. Details about the patient history and results of cranial imaging, audiological, vestibular and neurological assessments were collected retrospectively. 
Tympanometry (226Hz oto-admittance) was conducted preceding the vestibular assessment to evaluate the middle ear status.

\section{(video) Head Impulse Test - (v)HIT}

The high-frequency semicircular canal function was evaluated through the Head Impulse Test (HIT), which can be performed subjectively (with the naked eye, HIT) or objectively (with video-registration, vHIT). In both settings, the stimulus was nearly the same: the subject's head was rotated in the plane of the tested canal. For each HIT maneuver, an amplitude between $10^{\circ}$ to $20^{\circ}$ and a peak velocity above $120 \%$ s for the vertical and $150^{\circ} / \mathrm{s}$ for the lateral canals was pursued. Video Head Impulse Testing (version III, Synapsys Ulmer, Marseille, France) leads to several response parameters, of which we compared the VOR gain, asymmetry and ratio of corrective saccades to our center-specific normative values. Details about the test setup are outlined in Dhondt et al. (12).

\section{Rotatory test}

Mid-frequency horizontal semicircular canal function was examined with the rotatory test. Children were seated in a rotatory chair (version 1.70; Toennies Nystagliner, Höchberg, Germany) in a completely darkened room. Older children were fastened to the chair with a safety belt and the head stabilized in a head rest, younger children sat on their parent's lap, with the head manually fixated by the parent. $\mathrm{Ag} / \mathrm{AgCl}$ electrodes were placed bitemporally with a ground electrode on the forehead to register horizontal eye movements. A monocular infra- and supraorbital electrode placement was adopted to monitor eye blinks exclusively. To maintain alertness during rotation, children were stimulated to perform mental tasks (e.g. singing, talking about hobbies, etc.). A sinusoidal harmonic acceleration stimulus was used at the frequencies $0.01,0.05$, and $0.1 \mathrm{~Hz}$ with a peak velocity of 50 degrees/s. Response parameters gain, phase, and asymmetry were compared to our age-appropriate normative data, published by Maes et al. (13). 
The caloric test was used to evaluate low-frequency horizontal semicircular canal function. Subjects were placed in supine position with the head elevated $30^{\circ}$. Tests were performed in a semidarkened room with eyes open, wearing video goggles. For electronystagmographic (ENG) recording, the same electrode positioning as for the rotatory test was adopted. Subjects were again asked to perform mental tasks. Water irrigations were performed with the Variotherm Plus (Atmos, Medizin Tecknik, Lenzkirch, Germany). Temperatures of $30^{\circ} \mathrm{C}$ and $44^{\circ} \mathrm{C}$, a volume of $250 \mathrm{ml}$, and irrigation duration of 45 seconds were used. The full canalogram with four irrigations was pursued, but some patients only tolerated the cool irrigations. Only unilateral weakness (UW) was interpreted as response parameter, using the Jongkees' criterion. UW above $18 \%$ was considered significant (14). However, patients with significant (>18\%) UW in this study had values even above $25 \%$.

\section{Cervical Vestibular Evoked Myogenic Potentials - cVEMP}

Saccular function was examined with the cVEMP. The child was lying down and stimulated to rotate the head sideward using a video screen or toys. Background electromyographic (EMG) activity was monitored visually and recorded with a commercial system (Bio-Logic NavigatorPro platform, Mundelein, Illinios) using self-adhesive electrodes, with the noninverting electrodes placed at the midpoint of the sternocleidomastoid muscles, the inverting electrode on the sternoclavicular junction, and the ground electrode on the forehead. Bone conducted linear $500 \mathrm{~Hz}$ tone bursts $(1-2-1 \mathrm{~ms})$ were presented at an intensity of $59 \mathrm{dBnHL}$ and a $5 \mathrm{~Hz}$ stimulus repetition rate. The EMG-signals were amplified (5000 times) and band-pass filtered (10 to $1500 \mathrm{~Hz}$ ). Because of the children's young age, cVEMP-responses were interpreted as on/off-phenomena, without evaluation of response parameters. 
The oVEMP-test provided information on the utricular function. While lying down, the child was stimulated to maintain an upward gaze of $30^{\circ}$ by displaying an attractive visual target. EMG-activity was recorded (Bio-Logic Navigator-Pro platform, Mundelein, Illinois) using self-adhesive electrodes in 'nose position' configuration, described by Vanspauwen et al. (15) and Leyssens et al. (16). The active electrodes were placed just below the lateral canthus and on the inferior oblique muscle, the reference electrodes were placed close to the medial canthus on the nose and the ground electrode on the forehead. Air-conducted $500 \mathrm{~Hz}$ tone bursts (1-4$1 \mathrm{~ms}$ ) with an intensity of $95 \mathrm{dBnHL}$, a stimulus rate of $5.1 \mathrm{~Hz}$ and a total of 100 stimulus repetitions were delivered by insert earphones. Stimuli were delivered monaurally and responses were recorded unilaterally. The EMG-signals were amplified (5000 times) and bandpass filtered (1 to $500 \mathrm{~Hz}$ ). Just like the cVEMP-responses, oVEMP-responses were interpreted as on/off-phenomena.

\section{RESULts}

Since 2010 up until now, five patients followed at our service met the inclusion criteria and were selected for this case series. One of them (case 1) was asymptomatic, the other four (case 2-5) were symptomatic and received antiviral treatment.

A detailed overview of the characteristics of the episodes is given in Table 1. This table also provides a summary of the results on the electroencephalography (EEG) examinations, temporal bone imaging and peripheral vestibular assessments. Not all cases were subjected to the complete vestibular test battery, as is clarified in Table 1.

\subsection{Case 1}

A 2-year-old boy with an asymptomatic cCMV-infection and normal results on cranial magnetic resonance imaging (cMRI) at birth, was referred to our clinic in May 2010 because 
of recurrent symptoms of vertigo, vomiting, instability and nystagmus, after some time also accompanied with headache and photophobia. At the age of 1 year, he was diagnosed with delayed onset right-sided SNHL (65 dBnHL) which eventually progressed to right-sided deafness accompanied with delayed onset SNHL on the left side. Later on, he showed a developmental coordination disorder (DCD), dyscalculia, and dysorthographia. During the course of the follow-up, the boy had one vestibular examination, which was normal. At present, the boy is still suffering from vertigo-attacks, although the characteristics of the attacks have changed over the years and the frequency has decreased (currently 1 to 2 attacks a year).

\subsection{Case 2}

In January 2012, an 8-year-old girl consulted our clinic suffering from attacks of vertigo, vomiting, hypotonia and nystagmus. She also reported associated headache. At birth, she was diagnosed with a symptomatic cCMV-infection characterized by right-sided hearing loss and severe anomalies (subependymal pseudocysts, striatal vasculopathy, ventriculomegaly, periventricular tissue loss, subcortical white matter lesions, cortical dysplasia) on cranial imaging. During childhood, the girl showed delayed speech and language development, cerebral palsy, and left-sided strabismus. Due to deterioration of the hearing comprising bilateral moderate SNHL at 1 year of age with later progression to profound SNHL on the right side at 4 years of age, CI of the right ear was performed at the age of 5. Because of further progression of the hearing loss in the left ear, contralateral CI was performed two years later. Since the evolution to bilateral deafness the girl has been suffering from vertigo-attacks. The duration of the attacks has decreased over the years (initially 5 days, currently only 4 hours). She was repeatedly subjected to extensive vestibular assessment, which demonstrated fluctuation of the vestibular function.

\subsection{Case 3}


The third cCMV-patient suffering from paroxysmal vestibular symptoms was almost 3 when he came to our clinic in 2014 . The parents reported vomiting, instability and fearfulness. He was diagnosed at birth with a symptomatic cCMV-infection, marked by left-sided SNHL (70 dBnHL) and multifocal cerebral leukomalacia on cMRI. A year later, hearing deteriorated to severe right-sided and profound left-sided SNHL, for which sequential CI was performed at 2 (left) and 6 (right) years of age. A few months after deterioration of the hearing and first CI, the boy endured two episodes of vestibular symptoms in rapid succession, after which he was attack-free. Recently, an asymmetric response was detected on the caloric test. All other vestibular examinations were normal.

\subsection{Case 4}

A fourth patient was diagnosed with a symptomatic cCMV-infection at birth with clinical symptoms (purpura, petechiae, hypertonia), thrombocytopenia, abnormalities on cranial imaging (striatal vasculopathy, subependymal microcysts), and bilateral SNHL (50 and $60 \mathrm{dBnHL}$ in the left and right ear, respectively) which resulted in delayed language and motor development. After initial fluctuation of the hearing loss, progression to bilateral profound SNHL led to the decision of bilateral sequential CI at 4 (left) and 5 (right) years of age. After the first implantation, only temporary vertigo-complaints were reported. However, when the boy was nearly 7 , he experienced recurrent attacks of vertigo, vomiting and nystagmus, associated with headache. In this context, he was assessed in our clinic in January 2016. Already at the age of 4, bilateral vestibular areflexia of the horizontal semicircular canal and saccule was established.

\subsection{Case 5}

Case 5 was diagnosed at birth with a symptomatic cCMV-infection. Abnormalities on neonatal examinations were right-sided deafness and diffuse white matter lesions on cMRI suggestive for leukomalacia. At the age of 4 months, she was referred for physiotherapy because of 
hypotonia and delayed motor development. Since the age of 6 months up until now, she has been suffering from attacks of which the characteristics have changed during the years. The attacks were previously characterized by nausea, vomiting and reduced consciousness and therefore suggestive of epilepsy. However, this diagnosis could never be confirmed. Later on, headache, photophobia and phonophobia predominated the episodes, so that they were believed to be migraine-related. Apart from the attacks, the girl also suffers from episodic vomiting, occurring about once a week.

Delayed onset fluctuating SNHL in the left ear was detected at the age of 2, but appeared to be resolved at final evaluation at our service. When she was almost 3 years old, the girl experienced one episode of frequent falls and severe balance problems without loss of consciousness, lasting for about a week. During childhood, she was also diagnosed with strabismus, narcolepsy, and DCD. Because of limited motor improvement despite extensive physical therapy, the girl's physiotherapist referred her in 2016, at the age of 11, to our clinic. Vestibular assessment was indicative for bilateral vestibular areflexia of the horizontal semicircular canal, saccule and utricle.

Several causes were proposed in the differential diagnosis of these five cases. The most common ones were epilepsy (in cases 1,2,4,5) and migraine variants (in cases 1,2,4,5). However, none of these diagnoses could be confirmed in the long term.

\section{Discussion}

To our knowledge, this is the first study describing a series of cCMV-patients suffering from episodic vestibular symptoms. Although the majority of the children were symptomatic at birth, one of them was born asymptomatic. The five patients showed wide variation in presentation. 
However, in all cases, the attacks were recurrent, accompanied with nausea and/or vomiting, and occurring without clear-cut trigger. All cCMV-children had pre-existing or co-occurring SNHL which was unstable in all cases, being delayed onset (case 1,2,3,5), fluctuating (case 4,5) or progressive (case 1-4). Four out of five children (case 2-5) had a peripheral vestibular dysfunction on final evaluation at our service. In two of them, the deficit was established before or without undergoing cochlear implantation. Only in case 1, the results of the vestibular examinations were not indicative for a peripheral vestibular dysfunction. It should be noted that this patient was evaluated only once.

This case study, as well as earlier research, suggests that not only the auditory, but also the vestibular function can be unstable in children with cCMV $(5,7,8)$. Possibly, both progressive or fluctuating hearing loss and late onset and/or recurrent vestibular symptoms in children with cCMV are caused by the same underlying pathophysiologic mechanism. According to most studies, audiovestibular sensory loss is the result of primary injuries to the stria vascularis and the dark cells, leading to an alteration of potassium homeostasis with secondary damage to the sensory cells $(17,18)$. Although the mechanisms behind the auditory fluctuations are not fully elucidated, it is hypothesized that latent presence and reactivation of the virus with direct cytopathic effects and/or localized inflammatory auto-immune responses could be involved (19-21). With respect to the vestibular system, fluctuation or progression of vestibular sensory loss could be the basis of recurrent symptoms in (some of) our cases.

Also, peripheral vestibular dysfunction combined with paroxysmal symptoms resembles endolymphatic hydrops, as both Huygen and Admiraal (8) and Weiss and Ronis (11) already suggested in their cCMV case report. Laboratory tests with inoculation of CMV in the endolymphatic sac of guinea pigs have demonstrated the development of endolymphatic hydrops through direct cytopathic effects (in seronegative animals) and inflammatory immune responses (in both seronegative and seropositive animals) (22). In addition, endolymphatic 
hydrops in cCMV-patients was reported in two human temporal bone studies $(23,24)$. More recently, Teissier et al. (17) showed in a histopathologic study in cCMV-infected fetuses that cytomegalic cells and inflammation can indeed occur in the endolymphatic sac, which plays a key role in the inner ear fluid homeostasis.

Not only cCMV, but also CI can induce endolymphatic hydrops. It is described in literature as a possible cause of recurrent postoperative vertigo in CI-patients (25-27). The hydrops could originate from a disruption of endolymphatic flow due to obstruction in the ductus reuniens or the cochlear duct in the hook portion of the cochlea, or due to damage to the lateral cochlear wall caused by implantation (28). This is important to take into account as three children (case 2-4) had CI.

It should be noted that distinctive auditory symptoms of endolymphatic hydrops could go unnoticed in our cCMV-cases (and in the pediatric cCMV-population in general) as tinnitus and aural fullness are often underreported in children $(29,30)$ and profound SNHL might be preexistent (case 2-5). Underdiagnosis and misdiagnosis of vestibular disorders are important issues particularly in the pediatric population, because both history taking and vestibular assessment are very challenging in young children and their symptoms are often completely different from those in adults $(31,32)$. This case series demonstrates that differential diagnosis in children with cCMV is even more complex given that several confounding factors (preexisting auditory/vestibular dysfunction, neurologic disorders, CI, ophthalmologic disorders, etc.) can occur.

For example, in four out of five children (case 1,2,4,5) the initial diagnosis of epilepsy was proposed. Epilepsy is a well-known sequel of cCMV and can be accompanied with vestibular symptoms (33). However, in none of our cases this diagnosis could be confirmed. In two 
children (case 1,5) anti-epileptic treatment was initiated but stopped after a short period because of persistence of the symptoms and/or normal EEG-results during the episodes.

Another diagnosis suggested in almost all cases (case 1,2,4,5) was migraine. Pediatric migrainevariants (benign paroxysmal vertigo of childhood, cyclic vomiting, etc.) are a common cause of episodic vestibular complaints in children (34). Indeed, several reported symptoms of our cases also fit a migraine-variant. Unfortunately, these diagnoses are mainly based on history taking and efficacy of drug treatment which both are not evident or sometimes even impossible in the pediatric population. Also, an important criterion in diagnosing a migraine-variant is the fact that the reported symptoms are not better accounted for by another disorder $(35,36)$. Therefore, the multiple morbidities (vestibular loss, neurologic disorders, etc.) that can occur in cCMV-patients, make the diagnosis of (pediatric) migraine variants less obvious, but not necessarily less likely.

With respect to this study, its retrospective design is an important limitation as it implies that certain details about the attacks are missing. Therefore, this case series aims to underline the importance of thorough and repeated history taking, complemented with results of investigations. cCMV-patients, in particular, require longitudinal, extensive and multidisciplinary follow-up to enable correct diagnosis and treatment when vestibular symptoms occur. Especially in case of altered consciousness, EEG is recommended to establish the diagnosis of epilepsy. Additionally, evaluation of the peripheral vestibular function with an extensive test protocol (12) should be part of a regular follow-up in cCMV-patients and should especially be repeated in cases of paroxysmal attacks of vomiting, vertigo or falls. This is necessary to uncover alterations in the peripheral function (case 2), possibly isolated to one part of the vestibular organ (case 3) and to avoid unnecessary or inefficient treatment. As case 1 and 5 provide evidence for possible early onset of the episodes, follow-up should be initiated at an early age. Although scientific and clinical resources are currently mainly focusing on 
symptomatic cCMV-patients, case 1 demonstrates that asymptomatic cCMV-patients should be followed closely as well.

Future research could provide more insight in the question whether peripheral vestibular deficits in similar cCMV-cases are related to either sensory loss due to an altered potassium homeostasis or the development of endolymphatic hydrops resulting from derangements in inner ear fluid homeostasis. Recent advancements in imaging techniques enabling the visualization of endolymphatic hydrops could be promising in this respect.

In conclusion, diagnosis concerning episodic vestibular symptoms in children with cCMV is complex as several confounding factors (preexisting auditory/vestibular dysfunction, neurologic disorders, CI, etc.) can occur. Therefore, in this population, there is a need for greater awareness for vestibular disorders and longitudinal multidisciplinary follow-up to enable correct diagnosis and treatment.

\section{ACKNOWLEDGMENTS}

The authors would like to thank Prof. Dr. Els De Leenheer, Prof. Dr. Helen Van Hoecke and Dr. Alexandra De Kegel for introducing some of these interesting cases and their follow-up assessments, as well as the neuropaediatricians following these children for sharing their data, and the parents for giving consent to include the data of their child. 


\section{REFERENCES}

1. Kenneson A, Cannon MJ. Review and meta-analysis of the epidemiology of congenital cytomegalovirus (CMV) infection. Rev Med Virol 2007;17:253-76.

2. Goderis J, Keymeulen A, Smets K, et al. Hearing in Children with Congenital Cytomegalovirus Infection: Results of a Longitudinal Study. J Pediatr 2016;172:1105.e2.

3. Pappas DG. Hearing impairments and vestibular abnormalities among children with subclinical cytomegalovirus. Ann Otol Rhinol Laryngol 1983;92:552-7.

4. Karltorp E, Lofkvist U, Lewensohn-Fuchs I, et al. Impaired balance and neurodevelopmental disabilities among children with congenital cytomegalovirus infection. Acta Paediatr 2014;103:1165-73.

5. Bernard S, Wiener-Vacher S, Van Den Abbeele T, Teissier N. Disorders in Children With Congenital Cytomegalovirus Infection. Pediatrics 2015;136:e887-95.

6. Maes L, De Kegel A, Van Waelvelde H, et al. Comparison of the Motor Performance and Vestibular Function in Infants with a Congenital Cytomegalovirus Infection or a Connexin 26 Mutation: A Preliminary Study. Ear Hear 2017;38:e49-e56.

7. Strauss M. A clinical pathologic study of hearing loss in congenital cytomegalovirus infection. Laryngoscope 1985;95:951-62.

8. Huygen PL, Admiraal RJ. Audiovestibular sequelae of congenital cytomegalovirus infection in 3 children presumably representing 3 symptomatically different types of delayed endolymphatic hydrops. Int J Pediatr Otorhinolaryngol 1996;35:143-54.

9. Zagolski O. Vestibular-evoked myogenic potentials and caloric stimulation in infants with congenital cytomegalovirus infection. J Laryngol Otol 2008;122:574-9. 
10. Rine RM, Cornwall G, Gan K, et al. Evidence of progressive delay of motor development in children with sensorineural hearing loss and concurrent vestibular dysfunction. Percept Mot Skills 2000;90:1101-12.

11. Weiss JS, Ronis ML. The otologic manifestations of cytomegalic inclusion disease - a case report. Trans Pa Acad Ophthalmol Otolaryngol 1977;30:52-4.

12. Dhondt C, Dhooge I, Maes L. Vestibular assessment in the pediatric population. Laryngoscope 2019;129:490-3.

13. Maes L, De Kegel A, Van Waelvelde H, Dhooge I. Rotatory and collic vestibular evoked myogenic potential testing in normal-hearing and hearing-impaired children. Ear Hear 2014;35:e21-32.

14. Maes L, Dhooge I, De Vel E, D'Haenens W, Bockstael A, Vinck BM. Water irrigation versus air insufflation: a comparison of two caloric test protocols. Int J Audiol 2007;46:263-9.

15. Vanspauwen R, Wuyts FL, Krijger S, Maes LK. Comparison of Different Electrode Configurations for the oVEMP With Bone-Conducted Vibration. Ear Hear 2017;38:205-11.

16. Leyssens L, Heinze B, Vinck B, et al. 'Standard' versus 'nose reference' electrode placement for measuring oVEMPs with air-conducted sound: Test-retest reliability and preliminary patient results. Clin Neurophysiol 2017;128:312-22.

17. Teissier N, Delezoide AL, Mas AE, et al. Inner ear lesions in congenital cytomegalovirus infection of human fetuses. Acta Neuropathol 2011;122:763-74.

18. Gabrielli L, Bonasoni MP, Santini D, et al. Human fetal inner ear involvement in congenital cytomegalovirus infection. Acta Neuropathol Commun 2013;1:63. 
19. McCollister FP, Simpson LC, Dahle AJ, et al. Hearing loss and congenital symptomatic cytomegalovirus infection: a case report of multidisciplinary longitudinal assessment and intervention. J Am Acad Audiol 1996;7:57-62.

20. Noyola DE, Demmler GJ, Williamson WD, et al. Cytomegalovirus urinary excretion and long term outcome in children with congenital cytomegalovirus infection. Congenital CMV Longitudinal Study Group. Pediatr Infect Dis J 2000;19:505-10.

21. Keithley EM, Woolf NK, Harris JP. Development of morphological and physiological changes in the cochlea induced by cytomegalovirus. Laryngoscope 1989;99:409-14.

22. Fukuda S, Keithley EM, Harris JP. The development of endolymphatic hydrops following CMV inoculation of the endolymphatic sac. Laryngoscope 1988;98:439-43.

23. Myers EN, Stool S. Cytomegalic inclusion disease of the inner ear. Laryngoscope 1968;78:1904-15.

24. Rarey KE, Davis LE. Temporal bone histopathology 14 years after cytomegalic inclusion disease: a case study. Laryngoscope 1993;103:904-9.

25. Kubo T, Yamamoto K, Iwaki T, Doi K, Tamura M. Different forms of dizziness occurring after cochlear implant. Eur Arch Otorhinolaryngol 2001;258:9-12.

26. Rah YC, Park JH, Park JH, Choi BY, Koo JW. Dizziness and vestibular function before and after cochlear implantation. Eur Arch Otorhinolaryngol 2016;273:3615-21.

27. Fina M, Skinner M, Goebel JA, Piccirillo JF, Neely JG, Black O. Vestibular dysfunction after cochlear implantation. Otol Neurotol 2003;24:234-42; discussion 42.

28. Handzel O, Burgess BJ, Nadol JB, Jr. Histopathology of the peripheral vestibular system after cochlear implantation in the human. Otol Neurotol 2006;27:57-64.

29. Brantberg K, Duan M, Falahat B. Meniere's disease in children aged 4-7 years. Acta Otolaryngol 2012;132:505-9. 
30. Miyahara M, Hirayama M, Yuta A, Takeuchi K, Inoki T. Too young to talk of vertigo? Lancet 2009;373:516.

31. Rine RM, Wiener-Vacher S. Evaluation and treatment of vestibular dysfunction in children. NeuroRehabilitation 2013;32:507-18.

32. Weiss AH, Phillips JO. Congenital and compensated vestibular dysfunction in childhood: an overlooked entity. J Child Neurol 2006;21:572-9.

33. Tarnutzer AA, Lee SH, Robinson KA, Kaplan PW, Newman-Toker DE. Clinical and electrographic findings in epileptic vertigo and dizziness: a systematic review. Neurology 2015;84:1595-604.

34. Jahn K, Langhagen T, Heinen F. Vertigo and dizziness in children. Curr Opin Neurol 2015;28:78-82.

35. Lempert T, Olesen J, Furman J, et al. Vestibular migraine: diagnostic criteria. J Vestib Res 2012;22:167-72.

36. Lagman-Bartolome AM, Lay C. Pediatric migraine variants: a review of epidemiology, diagnosis, treatment, and outcome. Curr Neurol Neurosci Rep 2015;15:34.

37. Wuyts FL, Van Rompaey V, Maes LK. "SO STONED": Common Sense Approach of the Dizzy Patient. Front Surg 2016;3:32. 


\begin{tabular}{|c|c|c|c|c|c|c|c|c|c|}
\hline & Symptoms & $\underline{\text { Often }}$ & Since & Trigger & Otology & Neurology & Evolution & Duration & Investigations \\
\hline & $\begin{array}{l}\text { Vertigo, } \\
\text { nausea, } \\
\text { vomiting, } \\
\text { hypotonia, } \\
\text { instability, } \\
\text { headache, } \\
\text { photophobia, } \\
\text { nystagmus } \\
\end{array}$ & $\begin{array}{l}1-2 \\
\text { attacks/yr } \\
\text { (predo- } \\
\text { minantly } \\
\text { in } \\
\text { summer) }\end{array}$ & $\begin{array}{l}\text { Age: } \\
2 ; 0 \text { yr } \\
\text { Onset at } \\
\text { night or } \\
\text { early in } \\
\text { the mor- } \\
\text { ning }\end{array}$ & $\begin{array}{l}\text { Fatigue, } \\
\text { climate/daily } \\
\text { routine changes, } \\
\text { traumatic } \\
\text { events, stress, } \\
\text { overstimulation } \\
( \pm 2-4 \text { d before } \\
\text { attack-onset }) \\
\end{array}$ & $\begin{array}{l}\text { Preexisting delayed onset } \\
\text { progressive SNHL right (since } \\
\text { age } 1 \text { yr) and delayed onset } \\
\text { SNHL left (since age } 8 \text { yr) }\end{array}$ & $\begin{array}{l}\text { Headache } \\
\text { (holocranial), } \\
\text { preceding } \\
\text { aura, } \\
\text { photophobia, } \\
\text { reduced } \\
\text { alertness, } \\
\text { lethargy } \\
\end{array}$ & $\begin{array}{l}\text { Still suffering } \\
\text { from attacks } \\
\text { Current age: } \\
10 ; 7 \mathrm{yr}\end{array}$ & $\begin{array}{l}\cdot \text { Attacks of vertigo: } \\
10-15 \mathrm{~s} \\
\cdot \text { Several vertigo-attacks } \\
\text { with associated nausea, } \\
\text { headache, etc.: } 4-5 \mathrm{hr} \\
\text { - Total duration of episode } \\
\text { of feeling unwell: } 5 \mathrm{~d} \\
\text { (with attacks every day) } \\
\end{array}$ & $\begin{array}{l}\text { EEG (between as well as during attacks): no epileptic activity } \\
\text { - MRI temporal bone: normal } \\
\text { Vestibular assessment } \\
\text {. After onset vertigo-attacks - rotatory/caloric/cVEMP: normal } \\
\text { - Positional tests during attacks: normal } \\
\end{array}$ \\
\hline שֶّ & $\begin{array}{l}\text { Vertigo, } \\
\text { nausea, } \\
\text { vomiting, } \\
\text { hypotonia, } \\
\text { headache, } \\
\text { nystagmus }\end{array}$ & $\begin{array}{l}\text { Every } \\
3 \text { mos }\end{array}$ & $\begin{array}{l}\text { Age: } \\
7 ; 3 \mathrm{yr}\end{array}$ & $\begin{array}{l}\text { Spontaneous or } \\
\text { fatigue } \\
\text { combined with } \\
\text { overstimulation } \\
\text { (worsening } \\
\text { when changing } \\
\text { position) }\end{array}$ & $\begin{array}{l}\text { Preexisting bilateral } \\
\text { progressive profound SNHL } \\
\text { (right congenital, left delayed } \\
\text { onset) and bilateral CI }\end{array}$ & $\begin{array}{l}\text { Headache } \\
\text { (frontal, } \\
\text { bilateral) }\end{array}$ & $\begin{array}{l}\text { Still suffering } \\
\text { from attacks } \\
\text { Current age: } \\
15 ; 7 \mathrm{yr}\end{array}$ & Hours to days & 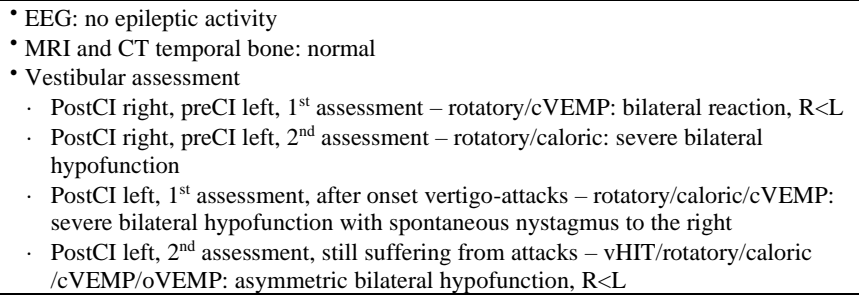 \\
\hline $\begin{array}{l}0 \\
\ddot{n} \\
\tilde{z}\end{array}$ & $\begin{array}{l}\text { Vomiting (only } \\
\text { the } 1^{\text {th attack), }} \\
\text { instability, } \\
\text { frequent falls, } \\
\text { panic, fear }\end{array}$ & $\begin{array}{l}2 \text { attacks } \\
\text { in total } \\
\text { with a } \\
\text { 2-day } \\
\text { interval }\end{array}$ & $\begin{array}{l}\text { Age: } \\
2 ; 10 \mathrm{yr}\end{array}$ & $\begin{array}{l}\text { Spontaneous, no } \\
\text { apparent trigger } \\
\text { (1) in the } \\
\text { evening } \\
\text { (2) in the } \\
\text { morning }\end{array}$ & $\begin{array}{l}\text { Preexisting progressive } \\
\text { profound SNHL left and } \\
\text { delayed onset progressive } \\
\text { moderately severe SNHL } \\
\text { right, CI left (long after the } \\
\text { attacks also CI right), frequent } \\
\text { episodes of OME }\end{array}$ & None & $\begin{array}{l}\text { Attack-free } \\
\text { Current age: } \\
7 ; 7 \text { yr }\end{array}$ & $\begin{array}{l}\text { (1) } 2 \mathrm{hr} \\
\text { (2) } 30 \mathrm{~min}\end{array}$ & $\begin{array}{l}\text { MRI and CT temporal bone: normal } \\
\text { - Vestibular assessment } \\
\text { PreCI - cVEMP: normal } \\
\text {. PostCI left, preCI right -cVEMP: normal } \\
\text {. After onset of the vertigo-attacks - rotatory/cVEMP: normal } \\
\text {. PostCI right, when already attack-free - vHIT/rotatory/caloric/cVEMP/oVEMP: } \\
\text { normal, except for asymmetric response on caloric test, } \mathrm{R}<\mathrm{L} \\
\end{array}$ \\
\hline נֶ, & $\begin{array}{l}\text { Vertigo, } \\
\text { nausea, } \\
\text { vomiting, } \\
\text { headache, } \\
\text { nystagmus }\end{array}$ & $\begin{array}{l}3 \text { attacks } \\
\text { in total } \\
\text { with a 2- } \\
\text { week } \\
\text { interval }\end{array}$ & $\begin{array}{l}\text { Age: } \\
6 ; 10 \mathrm{yr}\end{array}$ & $\begin{array}{l}\text { Spontaneous, no } \\
\text { apparent trigger }\end{array}$ & $\begin{array}{l}\text { Preexisting fluctuating and } \\
\text { progressive bilateral profound } \\
\text { SNHL, bilateral CI, } \\
\text { preexisting hyperacusis, } \\
\text { frequent episodes of OME }\end{array}$ & Headache & $\begin{array}{l}\text { Attack-free } \\
\text { Current age: } \\
9 ; 10 \mathrm{yr}\end{array}$ & $20 \mathrm{~min}$ to hours & $\begin{array}{l}\text { - EEG: no epileptic activity } \\
\text { - MRI and CT temporal bone: normal } \\
\text { - Vestibular assessment } \\
\text { PreCI - HIT/rotatory/cVEMP: bilateral areflexia } \\
\text {. PostCI left, preCI right - rotatory/cVEMP: bilateral areflexia } \\
\text {. PostCI right, after onset vertigo-attacks - rotatory/caloric/cVEMP: bilateral } \\
\text { areflexia }\end{array}$ \\
\hline $\begin{array}{l}n \\
0 \\
\tilde{z} \\
\tilde{z}\end{array}$ & $\begin{array}{l}\text { Balance } \\
\text { problems, } \\
\text { frequent falls }\end{array}$ & 1 episode & $\begin{array}{l}\text { Age: } \\
2 ; 8 \mathrm{yr}\end{array}$ & $\begin{array}{l}\text { Spontaneous, no } \\
\text { apparent trigger }\end{array}$ & $\begin{array}{l}\text { Preexisting congenital } \\
\text { profound SNHL right and } \\
\text { delayed onset fluctuating mild } \\
\text { SNHL left }\end{array}$ & None & $\begin{array}{l}\text { Spontaneous } \\
\text { recovery } \\
\text { Current age: } \\
13 ; 3 \mathrm{yr} \\
\end{array}$ & $\begin{array}{l}1 \mathrm{wk} \text { (with dozens of falls } \\
\text { every day) }\end{array}$ & $\begin{array}{l}- \text { EEG: no epileptic activity } \\
\cdot \text { Vestibular assessment } \\
.8 \text { years after the episode - vHIT/rotatory/caloric/cVEMP/oVEMP: bilateral } \\
\text { areflexia }\end{array}$ \\
\hline & alo & & & & 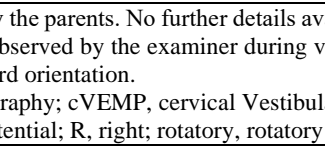 & & & & $\begin{array}{l}\text { st, leftward orientation. Nystagmus during } 2^{\mathrm{n}} \text { episode observed } \\
\text { t; L, left; MRI, magnetic resonance imaging; OME, otitis media }\end{array}$ \\
\hline
\end{tabular}

